\title{
Urinary CD80: a biomarker for a favorable response to corticosteroids in minimal change disease
}

\author{
Gabriel Cara-Fuentes ${ }^{1}$ - Miguel A Lanaspa ${ }^{2}$ - Gabriela E. Garcia ${ }^{2}$ - Mindy Banks ${ }^{3}$. Eduardo H. Garin ${ }^{4}$. \\ Richard J. Johnson ${ }^{2}$
}

Received: 27 November 2017 / Accepted: 4 January 2018 / Published online: 1 March 2018

(C) IPNA 2018

\begin{abstract}
Minimal Change Disease (MCD) is the most common type of nephrotic syndrome in children. The etiology has remained unknown, although it is commonly thought to be due to an unknown circulating factor that triggers podocyte dysfunction. To date, several changes in podocytes have been reported in MCD, of which one is the expression of CD80, also known as B7.1, which is a costimulatory molecule that is normally expressed on antigen -presenting cells. Some studies suggest that subjects with steroid-sensitive MCD may express CD80 in their podocytes during relapse and that this expression is associated with high urinary levels of CD80. Indeed, subjects with MCD in remission, or subjects with other glomerular diseases, such as focal segmental glomerulosclerosis, have substantially lower levels of urinary CD80 excretion. A recent study has now reported that high levels of urinary CD80 may be a sensitive marker for steroid-sensitivity and that their presence is also associated with longterm preservation of renal function. Thus, urinary CD80 is emerging as a potential biomarker for steroid-responsiveness in children presenting with primary nephrotic syndrome.
\end{abstract}

Keywords Nephrotic syndrome $\cdot$ Minimal change disease $\cdot$ CD80 $\cdot$ Focal segmental glomerulosclerosis

In 2004, Reiser et al. reported that under certain conditions podocytes can express cluster of differentiation 80 (CD80; also known as B7.1) [1], a costimulatory molecule normally expressed by antigen-presenting cells. Others subsequently confirmed that podocytes can function as antigen-presenting cells, suggesting additional functions of the podocyte in biology and evolution [2].

Miguel A Lanaspa

Miguel.lanaspagarcia@ucdenver.edu

1 Division of Pediatric Nephrology, University of Michigan, Ann Arbor, MI, USA

2 Division of Renal Diseases and Hypertension, Department of Medicine, University of Colorado, Denver, CO, USA

3 Rocky Mountain Pediatric Kidney Center, Suite 330, 2055 High Street, Denver, CO, USA

4 Division of Pediatric Nephrology, Department of Pediatrics, University of Florida, Gainesville, FL, USA

\section{CD80 and glomerular disease: the controversy on the role of CD80 in focal segmental glomerulosclerosis}

The discovery that CD80 can be expressed by podocytes resulted in a series of studies with the aim to determine if this molecule might act as a biomarker, or mediator, of various glomerular diseases. CD80 was reported to be induced in podocytes in a variety of experimental glomerular disease models associated with proteinuria, including genetic models ( $\alpha 3$ integrin knockout and nephrin knockout), lupus models, diabetic nephropathy, and following the administration of tolllike receptor ligands (TLRL), such as lipopolysaccharide (LPS) and poly-IC, to mice [1, 3, 4]. Some clinical studies also reported CD80 to be variably expressed in podocytes in lupus nephritis, minimal change disease (MCD), focal segmental glomerulosclerosis (FSGS), and diabetic renal disease $[1,3,5,6]$, but these findings could not be confirmed in other studies [7-11]. In addition, CTLA-4, a protein receptor which binds CD80 and downregulates the CD80 response, has been suggested as a potential treatment for glomerular disease based on these findings, especially in subjects with FSGS [6]. However, while treatment with abatacept (CTLA-4 
immunoglobin) was initially reported as beneficial in FSGS [6], most subsequent reports have been disappointing [12, 13]. Thus, the story of CD80 as a potential biomarker and mediator of kidney disease has remained controversial.

Perhaps researchers are overthinking CD80 as being "black and white" in disease states when it may be a biomarker that is variably expressed in many glomerular diseases in response to podocyte injury. Indeed, if there is low-grade expression in disease, then blocking CD80 may not provide any additional protection from the underlying mechanism of injury. For example, in immune complex diseases there may actually be ongoing complement activation with inflammatory cells driving disease, in diabetes the presence of microvascular disease can drive hemodynamic changes with glomerular injury, and in some genetic diseases proteinuria results from alteration in slit diaphragm proteins.

\section{CD80 as a biomarker for steroid-sensitive MCD}

An exception to the above may be the diseases characterized by a lack of immune deposits or inflammation - such as MCD and FSGS. In this regard, the strongest evidence for a role for CD80 is in corticosteroid-sensitive MCD and not FSGS. The evidence for involvement of CD80 in MCD has been primarily based on the finding of markedly elevated levels of CD80 in the urine that are higher than those observed in other glomerular diseases, including FSGS [5, 14-17]. Our studies suggest that in MCD, CD80 expression occurs in the podocyte, likely from engagement via TLRL, and that the CD80 activation is associated with functional changes that may cause proteinuria $[4,18,19]$. Evidence that the induction of CD80 in podocytes may drive proteinuria and podocyte dysfunction has also been reported by Reiser et al. and Khullar et al. [1, 20]. Indeed, we also found a remarkable improvement in proteinuria in a child with recurrent MCD who was treated with abatacept, although relapse occurred rapidly [13].

In a article recently published in Pediatric Nephrology, Ling et al. reporte their evaluation of the level of urinary CD80 as a predictor for response and long-term outcome in children presenting with primary nephrotic syndrome [21]. A baseline level of $>328 \mathrm{ng} \mathrm{CD} 80 / \mathrm{g}$ creatinine was found to predict steroid responsiveness ( 97 vs. $48 \%$ for those under the cutoff) and also to protect against the development of CKD stage 2 or higher (2.8 vs. $33.3 \%$ for those under the cutoff).

These studies support elevated urinary CD80 excretion as a useful biomarker for steroid-sensitive primary nephrotic syndrome in children and raise the question of whether CD80 may have a causal role in this condition. It does not address the discrepancy in the literature on whether CD80 is present in glomeruli of subjects with MCD. However, some of the discrepancy may relate to the patient population, as the studies that could not find positive glomerular staining rarely noted if the subjects had corticosteroid-sensitive MCD, whether they were already responding (as CD80 excretion drops prior to full remission), and that some were not nephrotic [9]. Most importantly, in none of the negative studies was urinary CD80 measured, which has been shown to reflect the activity of the disease, including in the accompanying paper [21].

In summary, CD80 should remain a hot topic in pediatric nephrology. Urinary CD80 may be an attractive marker for steroid-sensitive nephrotic syndrome in pediatric patients. Additional studies are necessary to better understand the role of CD80 in the pathogenesis of the disease.

\section{Compliance with ethical standards}

Disclosure The authors declare that they have no conflicts of interest to disclose.

\section{References}

1. Reiser J, von Gersdorff G, Loos M, Oh J, Asanuma K, Giardino L, Rastaldi MP, Calvaresi N, Watanabe H, Schwarz K, Faul C, Kretzler M, Davidson A, Sugimoto H, Kalluri R, Sharpe AH, Kreidberg JA, Mundel P (2004) Induction of B7-1 in podocytes is associated with nephrotic syndrome. J Clin Invest 113:1390-1397

2. Goldwich A, Burkard M, Olke M, Daniel C, Amann K, Hugo C, Kurts C, Steinkasserer A, Gessner A (2013) Podocytes are nonhematopoietic professional antigen-presenting cells. J Am Soc Nephrol 24:906-916

3. Fiorina P, Vergani A, Bassi R, Niewczas MA, Altintas MM, Pezzolesi MG, D’Addio F, Chin M, Tezza S, Ben Nasr M, Mattinzoli D, Ikehata M, Corradi D, Schumacher V, Buvall L, Yu CC, Chang JM, La Rosa S, Finzi G, Solini A, Vincenti F, Rastaldi MP, Reiser J, Krolewski AS, Mundel PH, Sayegh MH (2014) Role of podocyte B7-1 in diabetic nephropathy. J Am Soc Nephrol 25: 1415-1429

4. Ishimoto T, Shimada M, Gabriela G, Kosugi T, Sato W, Lee PY, Lanaspa MA, Rivard C, Maruyama S, Garin EH, Johnson RJ (2013) Toll-like receptor 3 ligand, polyIC, induces proteinuria and glomerular CD80, and increases urinary CD80 in mice. Nephrol Dial Transplant 28:1439-1446

5. Garin EH, Diaz LN, Mu W, Wasserfall C, Araya C, Segal M, Johnson RJ (2009) Urinary CD80 excretion increases in idiopathic minimal-change disease. J Am Soc Nephrol 20:260-266

6. Yu CC, Fornoni A, Weins A, Hakroush S, Maiguel D, Sageshima J, Chen L, Ciancio G, Faridi MH, Behr D, Campbell KN, Chang JM, Chen HC, Oh J, Faul C, Arnaout MA, Fiorina P, Gupta V, Greka A, Burke GW 3rd, Mundel P (2013) Abatacept in B7-1-positive proteinuric kidney disease. N Engl J Med 369:2416-2423

7. Gagliardini E, Novelli R, Corna D, Zoja C, Ruggiero B, Benigni A, Remuzzi G (2016) B7-1 is not induced in podocytes of human and experimental diabetic nephropathy. J Am Soc Nephrol 27:999_ 1005

8. Novelli R, Gagliardini E, Ruggiero B, Benigni A, Remuzzi G (2016) Another piece of the puzzle of podocyte B7-1 expression: lupus nephritis. Nephron 133:129-138 
9. Novelli R, Gagliardini E, Ruggiero B, Benigni A, Remuzzi G (2016) Any value of podocyte B7-1 as a biomarker in human MCD and FSGS? Am J Physiol Renal Physiol 310:F335-F341

10. Lee SW, Baek SH, Paik JH, Kim S, Na KY, Chae DW, Chin HJ (2017) Tubular B7-1 expression parallels proteinuria levels, but not clinical outcomes in adult minimal change disease patients. Sci Rep 7:41859

11. Larsen CP, Messias NC, Walker PD (2014) B7-1 immunostaining in proteinuric kidney disease. Am J Kidney Dis 64:1001-1003

12. Alachkar N, Carter-Monroe N, Reiser J (2014) Abatacept in B7-1positive proteinuric kidney disease. N Engl J Med 370:1263-1264

13. Garin EH, Reiser J, Cara-Fuentes G, Wei C, Matar D, Wang H, Alachkar N, Johnson RJ (2015) Case series: CTLA4-IgG1 therapy in minimal change disease and focal segmental glomerulosclerosis. Pediatr Nephrol 30:469-477

14. Cara-Fuentes G, Johnson RJ, Reiser J, Garin EH (2014) CD80 and suPAR in patients with minimal change disease and focal segmental glomerulosclerosis: diagnostic and pathogenic significance: response. Pediatr Nephrol 29:1467-1468

15. Garin EH, Mu W, Arthur JM, Rivard CJ, Araya CE, Shimada M, Johnson RJ (2010) Urinary CD80 is elevated in minimal change disease but not in focal segmental glomerulosclerosis. Kidney Int 78:296-302

16. Ling C, Liu X, Shen Y, Chen Z, Fan J, Jiang Y, Meng Q (2015) Urinary CD80 levels as a diagnostic biomarker of minimal change disease. Pediatr Nephrol 30:309-316
17. Mishra OP, Kumar R, Narayan G, Srivastava P, Abhinay A, Prasad R, Singh A, Batra VV (2017) Toll-like receptor 3 (TLR-3), TLR-4 and CD80 expression in peripheral blood mononuclear cells and urinary CD80 levels in children with idiopathic nephrotic syndrome. Pediatr Nephrol 32:1355-1361

18. Shimada M, Ishimoto T, Lee PY, Lanaspa MA, Rivard CJ, RoncalJimenez CA, Wymer DT, Yamabe H, Mathieson PW, Saleem MA, Garin EH, Johnson RJ (2012) Toll-like receptor 3 ligands induce CD80 expression in human podocytes via an NF-kappaBdependent pathway. Nephrol Dial Transplant 27:81-89

19. Ishimoto T, Cara-Fuentes $\mathrm{G}$, Wang $\mathrm{H}$, Shimada $\mathrm{M}$, Wasserfall $\mathrm{CH}$, Winter WE, Rivard CJ, Araya CE, Saleem MA, Mathieson PW, Johnson RJ, Garin EH (2013) Serum from minimal change patients in relapse increases CD80 expression in cultured podocytes. Pediatr Nephrol 28:1803-1812

20. Khullar B, Balyan R, Oswal N, Jain N, Sharma A, Abdin MZ, Bagga A, Bhatnagar S, Wadhwa N, Natchu UCM, George A, Rath S, Bal V, Sopory S (2017) Interaction of CD80 with Neph1: a potential mechanism of podocyte injury. Clin Exp Nephrol. https://doi.org/10.1007/s10157-017-1489-3

21. Ling C, Liu X, Shen Y, Chen Z, Fan J, Jiang Y, Meng Q (2018) Urinary CD80 excretion is a predictor of good outcome in children with primary nephrotic syndrome. Pediatr Nephrol. https://doi.org/ 10.1007/s00467-018-3885-7 